AperTO - Archivio Istituzionale Open Access dell'Università di Torino

\title{
Amyotrophic lateral sclerosis and food intake
}

\section{This is a pre print version of the following article:}

Original Citation:

\section{Availability:}

This version is available http://hdl.handle.net/2318/1673172

since 2018-08-11T16:53:52Z

Published version:

DOI:10.1080/21678421.2017.1418002

Terms of use:

Open Access

Anyone can freely access the full text of works made available as "Open Access". Works made available under a Creative Commons license can be used according to the terms and conditions of said license. Use of all other works requires consent of the right holder (author or publisher) if not exempted from copyright protection by the applicable law. 


\section{AMYOTROPHIC LATERAL SCLEROSIS AND FOOD INTAKE}

\section{INTRODUCTION}

Amyotrophic lateral sclerosis (ALS) is a fatal neurodegenerative disease of unknown etiology. The origin of the disease is perhaps multifactorial and several genetic and environmental risk factors may be implicated. Many dietary factors have been investigated in order to verify their role in the onset or the progression of the disease. In recent years the role of vitamins, proteins, amino acids and other nutrients have been studied without showing a clear beneficial or adverse effect to the onset and/or the progression of the disease. Inadequate study designs, differing target populations, and lack of statistical power are possible explanations. In addition, there are no studies focusing on specific nutrients in ALS. On this background, we investigated dietary habits preceding ALS by performing a well-designed and adequately powered study in a representative sample of ALS patients and matched controls. The aim of the study was to verify if specific (combinations of) foods and nutrients could be risk factors or protective factors in the development of ALS.

\section{MATERIAL AND METHODS}

Patients with newly diagnosed ALS residing in three Italian administrative regions (Lombardy, Piedmont \& Aosta valley, and Apulia; total population 18.629.052, 2014 census) were included in a European prospective observational study from February 2011 through January 2015 as part of the Euro-MOTOR collaboration. Euro-MOTOR was a network of European population-based registries from The Netherlands, Ireland and Italy aimed to investigate genetic and environmental risk factors for ALS using a case-control design. The details of the study design are illustrated elsewhere ( $D^{\prime}$ Ovidio et al, ALS in press).

As part of the Euro-MOTOR collaboration, an ancillary study was performed in Italy aimed to know the alimentary habits in ALS cases and controls. For the purpose of this study, patients were included if they were aged 18 or older and had definite, probable or possible ALS according to the El Escorial (EE) diagnostic classification (WFN Research Group on Neuromuscular Disorders. El Escorial World Federation of Neurology criteria for the diagnosis of amyotrophic lateral sclerosis. J Neurol Sci 1994; 124(suppl): 96-107). We excluded individuals with other neurodegenerative 
disorders, patients with percutaneous endoscopic gastrostomy for more than 1 year and patients with relatives affected by ALS.

For each patient, a healthy control, matched for age ( \pm 5 years), sex and administrative region of residence, was selected by a general practitioner (1:1 ratio). After signed informed consent, cases and controls were interviewed by a trained investigator who filled a validated and reproducible food-frequency questionnaire (FFQ) (Decarli A, Franceschi S, Ferraroni M, et al. Validation of a food-frequency questionnaire to assess dietary intakes in cancer studies in Italy. Results for specific nutrients. Ann Epidemiol 1996;6:110-8.), which investigated habitual food intake before interview. In order to evaluate exposures preceding the onset of ALS symptoms, we excluded all subjects who had changed their diet in the 5 years before the study began.

The following data were also recorded in a structured questionnaire: date of enrolment, sex, date of birth, region of residence, tobacco smoking, coffee and alcohol intake, and body mass index (BMI). For ALS patients, details were collected on the EE diagnostic category, site of onset of symptoms (bulbar, limbs, thoracic/respiratory), the Amyotrophic Lateral Sclerosis Functional Rating Scale (ALSFRS) score at study entry, date of diagnosis, and duration of symptoms at diagnosis. The recorded information was transferred from the questionnaires onto a centralized database for analysis. The study was approved by Ethic Committee of all participating centers.

Daily intake of macronutrients (carbohydrates, i.e., sugars and starch, protein, fat, cholesterol, and fibers), micronutrients (vitamins and minerals), fatty acids, and total energy were estimated using an Italian food composition database (Gnagnarella P, Parpinel M, Salvini S, Franceschi S, Palli D, Boyle P. The update of the Italian food composition database. J Food Comp Analysis. 2004;17:509$522)$.

\section{Statistical analysis}

Descriptive statistics for ALS cases and controls are reported as frequencies and percentages, means and standard deviations (SD), medians, interquartile ranges (IQR) or ranges, as appropriate. Differences between cases and controls were assessed using the chi-square test, or the WilcoxonMann-Whitney test.

Food items included in the FFQ were combined into 21 groups: milk and yogurt; coffee and tea; white bread; whole bread; pasta and rice; soup; poultry; red meat; pork and processed meat; fish; eggs; cheese; raw vegetables; cooked vegetables; pulses; potatoes; citrus fruits; other fruits; 
desserts; sugar; and alcohol. In order to define in greater detail the relationship between coffee and tea consumption and the risk of ALS, three subgroups were identified and assessed separately: coffee (decaffeinated excluded); decaffeinated coffee; tea.

Food groups and nutrients were categorized into quartiles of intake in the entire sample (or using a more appropriate categorization for foods with low frequency of consumption). Conditional logistic regression models were used to evaluate the association between each food group, selected nutrients and the risk of ALS. All models were controlled for region, and sex (matching variables), and adjusted for age (5-year groups), BMI (<18.5; 18.5-24.9; 25-29.9; $\geq 30 \mathrm{~kg} / \mathrm{m}^{2}$ ), tobacco smoking (ever; never), alcohol drinking (ever; never), coffee consumption (ever; never) and total energy intake (continuous). Interactions of food groups and nutrients with sex, site of onset and administrative region were also tested.

Results are presented as odds ratios (OR), with $95 \%$ confidence intervals $(95 \% \mathrm{Cl})$. Missing data were present in less than $1 \%$ of subjects for each food item and were handled imputing the median intake of the corresponding missing food item, calculated on all available data. The significance level was set at $5 \%$. All analyses were performed using the SAS statistical package (version 9.2, SAS Institute Inc, Cary, NC, USA).

Ethical approval. The study protocal was approved by the Ethical Committees of all participating centers. All patients and controls signed an informed consent.

\section{RESULTS}

A total of 212 cases and 212 matched controls were included in the study. The sample included 188 females and 236 males. The main characteristics of ALS cases are illustrated in Table 1. The mean (SD) age and disease duration at the time of diagnosis were 62.6 (10.4) years and 13.2 (12.9) months, respectively. Most patients had a spinal onset (74.1\%), 24.1\% had a bulbar onset, and only $1.9 \%$ had a respiratory onset. The commonest EE diagnostic categories were probable ALS (42.9\%) and definite ALS (24.5\%). The mean (SD) time from diagnosis at the date of interview was 7.1 (5.5) months and the mean (SD) ALSFRS score was 37.3 (8.7).

Cases and controls were evenly distributed as regards tobacco, alcohol, coffee and total energy intake, while cases had a lower BMI as compared to controls (Table 2). 
A significant trend toward a risk reduction was found for coffee and tea $(\mathrm{OR}=0.29,95 \% \mathrm{Cl} 0.14-$ 0.60 for the highest versus the lowest quartile of consumption), whole bread (OR=0.55, $95 \% \mathrm{Cl}$ 0.31-0.99), raw vegetables $(\mathrm{OR}=0.25,95 \% \mathrm{Cl} 0.13-0.52)$ and citrus fruits $(\mathrm{OR}=0.49,95 \% \mathrm{Cl} 0.25-$ 0.97; Table 3). After separating coffee and tea into subgroups, a significant risk reduction was observed for decaffeinated coffee $(\mathrm{OR}=0.18,95 \% \mathrm{Cl} 0.06-0.57)$ and for tea $(\mathrm{OR}=0.36,95 \% \mathrm{Cl} 0.19$ 0.67), but not for coffee (excluding decaffeinated coffee). A significant risk increase was observed for red meat $(\mathrm{OR}=2.96,95 \% \mathrm{Cl} 1.46-5.99)$ and pork and processed meat $(\mathrm{OR}=3.87,95 \% \mathrm{Cl} 1.86$ 8.07).

No significant association with the risk of ALS was found for total energy intake (Table 4). A significant inverse association was observed for vegetable fat $(O R=0.25,95 \% \mathrm{Cl} 0.11-0.57$ for the highest versus the lowest quartile of intake), total folate (OR=0.41,95\% Cl 0.18-0.91), and vitamin $E(O R=0.40,95 \% \mathrm{Cl} 0.18-0.92)$.

A significantly increased risk was found for total protein (OR=2.96, 95\% Cl 1.08-8.10), animal protein $(\mathrm{OR}=2.91,95 \% \mathrm{Cl}$ 1.33-6.38), sodium (OR=3.96, 95\% Cl 1.45-10.84) and zinc (OR=2.78, 95\% $\mathrm{Cl}$ 1.01-7.83). A significant risk increase was also found for the highest versus the lowest quartile of glutamic acid intake (OR=3.63, 95\% $\mathrm{Cl} 1.08-12.2)$, though in the absence of a linear trend in risk. No significant interactions were found with sex, site of onset and administrative region (data not shown).

\section{DISCUSSION}

In this case-control study including data from three Italian administrative regions, differences were noted for intake of some food items/nutrients between ALS patients and controls. ALS patients reported a lower intake of decaffeinated coffee, tea, whole bread, raw vegetables, citrus fruit, as

well as of vegetable fats, folate, and vitamin E; conversely they reported a higher intake of (red and processed) meat and of proteins in general, as well as of sodium, zinc, and glutamic acid.

A favorable role of Vitamin E on the risk of ALS is suggested by its cellular antioxidant role that was shown in transgenic mice expressing mutations in gene encoding the antioxidant enzyme CU/Zn superoxide dismutase (SOD), an animal model of ALS (ref). In animal models, Vitamin E was associated with a decreased incidence and progression of the disease, but had no effect on survival; in addition, several cell experiments revealed a neuroprotective effect of alphatocopherol in ALS (D Allan Butterfield et al, Nutritional Neuroscienze 2002, vol 5). However, the 
use of antioxidant agents had no apparent beneficial effect on survival nor on disease progression in ALS patients (Orrell et al, ALS and FT disease, 10/07/2009). Our findings suggest that the effects of vitamin $\mathrm{E}$ on motor neurons may differ according to the modalities of intake (food vs. drug). The benefits of vitamin E present in the diet on ALS risk may depend on its possible interaction with other food components.

We found a significant inverse association between ALS, tea and decaffeinated coffee. Other studies investigated the association between coffee (caffeinated beverages, tea) and ALS risk or progression. A cohort study also observed a protective role of tea on ALS (Morozova et all 2008 Epidemiology), but, in contrast with our results, that study found that decaffeinated coffee was associated with an increased risk of ALS. An inverse association with coffee was found in an Italian case-control study (Coffee and amyotrophic lateral sclerosis: a possible preventive role. Beghi E, Pupillo E, Messina P, Giussani G, Chiò A, Zoccolella S, Moglia C, Corbo M, Logroscino G; EURALS Group. Am J Epidemiol. 2011 Nov 1;174(9):1002-8). However, that study was unable to identify the specific role of caffeine or other components of caffeinated beverages. The role of coffee was also investigated in a pooled-analysis of five cohorts in the US (Elinor Fondell et al, Amyotroph Lateral Scler Frontotemporal Degener 2015 September ; 16). In line with our findings, that study did not confirm an association between caffeine or caffeinated beverages and the risk of ALS. Both caffeinated and decaffeinated coffee have protective effects against neurodegeneration (Kim \& Lee, Coffee Volume, pp 423-427). Coffee has been shown to exhibit protective effects against Parkinson and Alzheimer disease (Barranco Quintana et al, 2007; Ross et al, 2000). Chlorogenic acid, caffeic acid, kahweol and trigonelline, may be involved as they also contribute to the neuropharmacological action of coffee. Caffeic acid, with ferulic and p-coumaric acid, is a phenolic acid interacting with lipid membranes and, as such, has beneficial effects through the prevention of neurodegenerative diseases (Chapter 89 Coffee Volume). Chlorogenic acid has antioxidant activity and is able to scavenge free radicals and interrupt radical chain reactions (Chapter 87 Coffee Volume). Kawheol, a coffee diterpene, has anti-inflammatory properties, modulates nitric oxide synthesis, and protects against oxidative stress (Chapter 70 Coffee Volume). The neuroprotective activity of these agents has been mostly documented in Parkinson disease but the possibility exists of a similar action in patients with ALS.

We also found an inverse association between folate intake and ALS. Folate deficiency is present in a variety neurological disorders, including Alzheimer disease, Parkinson disease and ALS (Mizrahi 
et al, 2003). A study (MAYA DUBEY and Thomas Shea, Nutritional Neuroscience, October 2007) has shown that folate deprivation increases the impact of arsenic neurotoxicity. As the toxicity of arsenic could be decreased with antioxidants intake (MAYA DUBEY and Thomas Shea, Nutritional Neuroscience, October 2007), an antioxidant deficit could enhance the toxic effects of arsenic in predisposed individuals resulting in neurodegeneration. The combined intake of folate and vitamin E together may have a strong effect against oxidative stress and ultimately decrease the risk of ALS.

We also investigated the role of whole bread in ALS onset and found an inverse association. This finding was confirmed by a cohort study (Morozova 2008, Epidemiology) in patients aged 65 or older, a population largely overlapping our sample. However, we did not find an inverse association between fibers and ALS. Fibers have a low concentration of markers of inflammation which has a key role in the pathogenesis of ALS (Philips t et al, Lancet Neurol 2011) - (qi I et al, Diabetes care 2006; Chuang SC et al, Biomarkers 2011) and a high fiber intake has been associated with a lower risk of ALS (Nelson LM et al, Am J Epidemiol 2000). We found a borderline increased association between glutamic acid and ALS. Glutamate is a cytotoxic substance involved in the pathogenesis of ALS (Morozova 2008, Epidemiology). The overexcitation of glutamate receptors leads to the elevation of the intracellular calcium causing the selective neuron death that is the primary cause of ALS. Glutamate is available in food containing protein, tomatoes, mushrooms, milk and cheese, but the role of dietary glutamate intake in ALS is still unclear. Monosodium glutamate use is frequent in precooked food and in sausages, that are frequently used. Glutamate is metabolized as glutamic acid. We still do not known to what extent glutamate or glutamic acid are involved in ALS process. The prospective cohort study by Morozova et al (2008) aimed to investigate the role of diet in the onset of cancer and other disorders, failed to show an association between red meat, vegetables or other products that are the primary source of glutamate and ALS onset while a strong inverse association was found for chicken consumption. The different study design may explain the differences between that study, that did not investigate the role of nutrients, and ours.

In agreement with us, a population-based case-control study (Nelson 2000 AJE) and a cohort study (Morozova 2008, Epidemiology; Fondell 2014 AJE) reported an inverse association between fruits and vegetables intake and risk of ALS. Fruits were also investigated in Japanese case-control studies. Jin et al (Jin 2014 Nutritional Neuroscience) and Okamoto et Al (Okamoto 2008 
Neuroepidemiology) reported a significant inverse association between fruit intake and risk of ALS. Fruits and vegetables are rich of antioxidant vitamins and minerals (Van Duyn et al J Am Diet Assoc 2000; 100: 1511-21, Binazzi et Al ALSFTD 2009). An increased intake of fruits and vegetables may thus protect against oxidative stress as being free radical scavengers.

In addition, high intake of vegetables and fruits and low intake of processed meat were included among “Alzheimer disease protective” patterns (Berti et al, J Nutr Health Aging 2015; 19:413).

We found an increased risk of ALS for pork/processed meat, red meat, zinc and sodium. To our knowledge, these are no studies demonstrating the association of this food groups and nutrients with ALS. We found a significant linear correlation (above 0.5) between zinc and red meats (0.65), between zinc and pork/processed meats (0.54), and between sodium and processed meats (0.55). Our study has several strengths. First, we have looked at foods or food groups using a validated and reproducible FFQ and an Italian food composition database (Gnagnarella P, Parpinel M, Salvini S, Franceschi S, Palli D, Boyle P. The update of the Italian food composition database. J Food Comp Analysis. 2004;17:509-522; Salvini S, Parpinel M, Gnagnarella P et al. Milan, Italy: Istituto Europeo di Oncologia,1998). We have been also able to estimate the intake of selected nutrients, and thus to verify which specific elements could or could not be involved in the disease process. Second, this is the first population based case-control study with a fairly large sample size; controls were from general practitioners and were not family members, i.e. individuals with similar dietary habits. Third, we investigated the role of food intake during health status and in patients without percutaneous endoscopic gastrostomy.

The study has also limitations. This is an Italian study and, as such, the results are a reflection of the Italian diet, which differs from other diets mostly in the use of olive oil, coffee and vegetables. These findings thus require confirmation in other geographic areas where the alimentary habits are different from ours. Another limitation is inherent in the case-control design, which is subjected to recall bias. A third limitation is the possibility of reverse causation. We tried to investigate unchanged alimentary habits and excluded diets changed in the preceding five years. However, as the time of disease onset is unknown, we cannot exclude that dietary changes occurred during the course of the disease.

In conclusion, our findings support the hypothesis that some foods/nutrients may be risk factors and others protective factors for ALS. However, a definite answer to this controversial issue could 
be provided only by a larger and specific evaluation of few nutrients matched with specific genetic tests.

Acknowledgments: This work was supported by European Community's Health Seventh Framework Program 2007-2013 (grant agreement 259867. 
Table 1. Characteristics of ALS cases $(n=212)$

\begin{tabular}{lcc}
\hline & N & \% \\
\hline Site of onset & 51 & 24.1 \\
Bulbar & 157 & 74.1 \\
Spinal & 4 & 1.9 \\
Thoracic/respiratory & & \\
El Escorial category & 52 & 24.5 \\
$\begin{array}{l}\text { Definite } \\
\text { Possible }\end{array}$ & 48 & 22.71 \\
$\begin{array}{l}\text { Probable } \\
\text { Probable laboratory }\end{array}$ & 91 & 42.9 \\
supported & 21 & 9.9 \\
& & \\
& Mean & SD \\
Age at diagnosis & 62.6 & 10.4 \\
$\begin{array}{l}\text { Age at onset } \\
\text { Disease duration at } \\
\text { diagnosis (months) }\end{array}$ & 61.5 & 10.3 \\
Time from diagnosis & 13.2 & 12.9 \\
ALSFRS & 7.1 & 5.5 \\
\hline
\end{tabular}

SD: standard deviation.

ALSFRS: ALS Functional Rating Scale 
Table 2. Distribution of ALS cases ( $n=212)$ and controls $(n=212)$ according to selected variables

\begin{tabular}{|c|c|c|c|c|c|}
\hline & \multicolumn{2}{|c|}{ ALS } & \multicolumn{2}{|c|}{ Controls } & \multirow[b]{2}{*}{ p-value } \\
\hline & $\mathbf{N}$ & $\%$ & $\mathbf{N}$ & $\%$ & \\
\hline \multicolumn{6}{|l|}{ Region* } \\
\hline Lombardy & 87 & 41.0 & 87 & 41.0 & \\
\hline Piedmont & 87 & 41.0 & 87 & 41.0 & \\
\hline Puglia & 38 & 17.9 & 38 & 17.9 & \\
\hline \multicolumn{6}{|l|}{ Age (years)* } \\
\hline$<50$ & 25 & 11.8 & 24 & 11.3 & \\
\hline $50-54$ & 22 & 10.4 & 20 & 9.4 & \\
\hline $55-59$ & 24 & 11.3 & 19 & 9.0 & \\
\hline $60-64$ & 42 & 19.8 & 37 & 17.5 & \\
\hline $65-69$ & 44 & 20.8 & 48 & 22.6 & \\
\hline $70-74$ & 30 & 14.1 & 33 & 15.6 & \\
\hline $75+$ & 25 & 11.8 & 31 & 14.6 & \\
\hline \multicolumn{6}{|l|}{ Sex* } \\
\hline Female & 94 & 44.3 & 94 & 44.3 & \\
\hline Male & 118 & 55.7 & 118 & 55.7 & \\
\hline BMI (kg/m2) & & & & & 0.0479 \\
\hline Underweight $(<18.5)$ & 14 & 6.6 & 6 & 2.8 & \\
\hline Normal (18.5 - 24.9) & 115 & 54.3 & 98 & 46.2 & \\
\hline Overweight (25 - 29.9) & 63 & 29.7 & 80 & 37.7 & \\
\hline Obese $(\geq 30)$ & 20 & 9.4 & 28 & 13.2 & \\
\hline Tobacco smoking & & & & & 0.5586 \\
\hline Never & 94 & 44.3 & 100 & 47.2 & \\
\hline Ever & 118 & 55.7 & 112 & 52.8 & \\
\hline Alcohol drinking & & & & & 0.6663 \\
\hline Never & 62 & 29.3 & 58 & 27.4 & \\
\hline Ever & 150 & 70.7 & 154 & 72.6 & \\
\hline Coffee consumption & & & & & 0.1791 \\
\hline Never & 30 & 14.1 & 21 & 9.9 & \\
\hline \multirow[t]{2}{*}{ Ever } & 182 & 85.9 & 191 & 90.1 & \\
\hline & Median & IQR & Median & IQR & \\
\hline $\begin{array}{l}\text { Total energy intake } \\
\text { (kcal) }\end{array}$ & 1856 & $1571-2239$ & 1892 & $1552-2223$ & 0.8732 \\
\hline
\end{tabular}

*Matching variables 
BMI: Body Mass index

IQR: interquartile range. 
Table 3. Food groups: odds ratios of ALS according to quartiles of weekly consumption

\begin{tabular}{|c|c|c|c|c|c|c|c|c|c|}
\hline \multirow[b]{3}{*}{ Food group } & \multirow[b]{3}{*}{ Median } & \multirow[b]{3}{*}{ IQR } & \multicolumn{6}{|c|}{ Quartile of intake* } & \multirow{3}{*}{$\begin{array}{l}p \text {-value } \\
\text { for } \\
\text { trend }\end{array}$} \\
\hline & & & \multicolumn{2}{|r|}{2} & \multicolumn{2}{|r|}{3} & \multicolumn{2}{|r|}{4} & \\
\hline & & & OR & $95 \% \mathrm{Cl}$ & OR & $95 \% \mathrm{Cl}$ & OR & $95 \% \mathrm{Cl}$ & \\
\hline Milk and yogurt & 8.8 & $5.0-10.8$ & 1.07 & $0.61-1.89$ & 0.93 & $0.48-1.77$ & 1.10 & $0.61-1.99$ & 0.8663 \\
\hline Coffee and tea & 10.5 & $5.3-15.8$ & 0.62 & $0.35-1.09$ & 0.98 & $0.52-1.85$ & 0.29 & $0.14-0.60$ & 0.0079 \\
\hline Coffee (decaffeinated excluded) & 7.5 & $5.3-13.5$ & 1.10 & $0.50-2.43$ & 0.69 & $0.40-1.19$ & 1.19 & $0.67-2.12$ & 0.9482 \\
\hline Decaffeinated coffee ${ }^{1}$ & 0.0 & $0.0-0.0$ & 0.37 & $0.13-1.03$ & 0.18 & $0.06-0.57$ & & & 0.0007 \\
\hline $\mathrm{Tea}^{2}$ & 0.0 & $0.0-1.0$ & 0.86 & $0.46-1.59$ & 0.36 & $0.19-0.67$ & & & 0.0021 \\
\hline White bread & 9.0 & $5.7-15.5$ & 0.69 & $0.38-1.24$ & 0.84 & $0.44-1.61$ & 0.91 & $0.45-1.82$ & 0.8710 \\
\hline Whole bread ${ }^{3}$ & 0.0 & $0.0-1.8$ & 0.57 & $0.30-1.09$ & 0.55 & $0.31-0.99$ & & & 0.0323 \\
\hline Pasta and rice & 4.9 & $3.4-6.9$ & 1.38 & $0.74-2.57$ & 1.16 & $0.60-2.24$ & 1.28 & $0.64-2.58$ & 0.6423 \\
\hline Soup & 1.4 & $0.6-3.0$ & 1.37 & $0.79-2.39$ & 1.31 & $0.72-2.37$ & 1.54 & $0.81-2.95$ & 0.2073 \\
\hline Poultry & 1.8 & $1.0-2.5$ & 0.93 & $0.50-1.75$ & 0.82 & $0.46-1.47$ & 1.83 & $0.96-3.48$ & 0.1844 \\
\hline Red meat & 2.2 & $1.4-3.2$ & 1.74 & $0.94-3.22$ & 1.55 & $0.84-2.85$ & 2.96 & $1.46-5.99$ & 0.0060 \\
\hline Pork and processed meat & 2.3 & $1.3-3.4$ & 1.44 & $0.75-2.77$ & 1.60 & $0.83-3.07$ & 3.87 & $1.86-8.07$ & 0.0006 \\
\hline Fish & 2.0 & $1.3-2.8$ & 1.08 & $0.59-1.97$ & 1.21 & $0.67-2.22$ & 0.69 & $0.37-1.30$ & 0.3946 \\
\hline Eggs & 1.0 & $0.8-2.0$ & 0.60 & $0.34-1.08$ & 0.82 & $0.47-1.45$ & 0.64 & $0.32-1.28$ & 0.3406 \\
\hline Cheese & 2.8 & $1.5-4.3$ & 0.73 & $0.38-1.43$ & 0.97 & $0.53-1.77$ & 0.55 & $0.27-1.10$ & 0.2221 \\
\hline Raw vegetables & 7.5 & $4.4-11.3$ & 0.46 & $0.24-0.86$ & 0.56 & $0.30-1.05$ & 0.25 & $0.13-0.52$ & 0.0005 \\
\hline Cooked vegetables & 4.4 & $3.0-6.7$ & 0.91 & $0.49-1.68$ & 0.67 & $0.36-1.22$ & 0.79 & $0.43-1.48$ & 0.3119 \\
\hline Pulses & 1.0 & $0.5-2.0$ & 1.19 & $0.67-2.14$ & 0.88 & $0.48-1.62$ & 1.24 & $0.58-2.63$ & 0.9732 \\
\hline
\end{tabular}




\begin{tabular}{lccccccccc} 
Potatoes & 1.3 & $1.0-2.0$ & 0.95 & $0.44-2.05$ & 0.64 & $0.36-1.13$ & 1.18 & $0.66-2.12$ & 0.8969 \\
Citrus fruits & 6.0 & $3.0-7.0$ & 0.44 & $0.23-0.86$ & 0.41 & $0.22-0.77$ & 0.49 & $0.25-0.97$ & 0.0198 \\
Other fruits & 20.0 & $14.5-28.0$ & 0.81 & $0.45-1.47$ & 0.52 & $0.29-0.93$ & 0.78 & $0.37-1.60$ & 0.1339 \\
Desserts & 6.3 & $3.0-9.8$ & 0.77 & $0.42-1.41$ & 0.97 & $0.52-1.82$ & 1.43 & $0.76-2.68$ & 0.2167 \\
Sugar & 7.5 & $5.3-13.5$ & 1.09 & $0.60-1.99$ & 1.01 & $0.57-1.79$ & 1.04 & $0.58-1.89$ & 0.9574 \\
Alcohol & 7.0 & $0.0-14.0$ & 0.67 & $0.34-1.32$ & 0.76 & $0.37-1.57$ & 0.49 & $0.22-1.08$ & 0.1310 \\
\hline
\end{tabular}

All models were controlled for region, age and sex (matching variables), and adjusted for BMI $\left(<18.5 ; 18.5-24.9 ; 25-29.9 ; \geq 30 \mathrm{~kg} / \mathrm{m}^{2}\right)$, tobacco smoking (ever; never), alcohol drinking (ever; never), coffee consumption (ever; never) and total energy intake (continuous).

IQR: interquartile range; OR: odds ratio; $\mathrm{Cl}$ : confidence interval.

*reference category: first quartile;

${ }^{1}$ reference category: 0 cups; category $2:<7$ cups per week; category $3: \geq 7$ cups per week;

${ }^{2}$ reference category: 0 cups; category $2:<3$ cups per week; category $3: \geq 3$ cups per week;

${ }^{3}$ reference category: 0 portions per week; category 2: 1-4 portions per week; category 3: $>4$ portions per week 
Table 4. Total energy and selected nutrients: odds ratios of ALS according to quartiles of daily intake

\begin{tabular}{|c|c|c|c|c|c|c|c|c|c|}
\hline & \multirow[b]{3}{*}{ Mean } & \multirow[b]{3}{*}{ SD } & \multicolumn{6}{|c|}{ Quartile of intake* } & \multirow{3}{*}{$\begin{array}{l}\text { p-value } \\
\text { for } \\
\text { trend }\end{array}$} \\
\hline & & & \multicolumn{2}{|r|}{2} & \multicolumn{2}{|r|}{3} & \multicolumn{2}{|r|}{4} & \\
\hline & & & OR & $95 \% \mathrm{Cl}$ & OR & $95 \% \mathrm{Cl}$ & OR & $95 \% \mathrm{Cl}$ & \\
\hline Energy (kcal) & 1942.5 & 557.5 & 1.25 & $0.69-2.25$ & 1.01 & $0.54-1.89$ & 1.15 & $0.59-2.26$ & 0.8680 \\
\hline \multicolumn{10}{|l|}{ Macronutrients } \\
\hline Total protein (g) & 77.9 & 22.4 & 2.35 & $1.22-4.53$ & 2.31 & $1.09-4.89$ & 2.96 & $1.08-8.10$ & 0.0437 \\
\hline Animal protein (g) & 48.7 & 16.4 & 1.93 & $0.99-3.76$ & 2.25 & $1.17-4.33$ & 2.91 & $1.33-6.38$ & 0.0070 \\
\hline Vegetable protein (g) & 29.2 & 9.9 & 1.85 & $0.94-3.64$ & 1.25 & $0.59-2.61$ & 1.98 & $0.64-6.17$ & 0.4958 \\
\hline Available carbohydrates (g) & 251.3 & 80.7 & 2.15 & $1.06-4.37$ & 1.71 & $0.77-3.79$ & 2.21 & $0.70-6.93$ & 0.2925 \\
\hline Soluble carbohydrates (g) & 90.4 & 41.9 & 0.57 & $0.31-1.04$ & 0.84 & $0.44-1.63$ & 1.14 & $0.53-2.47$ & 0.6379 \\
\hline Starch (g) & 160.8 & 59.9 & 1.23 & $0.62-2.45$ & 0.93 & $0.47-1.86$ & 1.21 & $0.47-3.14$ & 0.9720 \\
\hline Fibers (g) & 23.3 & 9.4 & 0.78 & $0.42-1.45$ & 0.69 & $0.35-1.35$ & 0.80 & $0.35-1.85$ & 0.5034 \\
\hline Total fat (g) & 66.1 & 20.6 & 0.74 & $0.40-1.39$ & 1.01 & $0.48-2.15$ & 0.48 & $0.17-1.33$ & 0.3243 \\
\hline Animal fat (g) & 35.7 & 13.5 & 0.72 & $0.37-1.41$ & 2.11 & $1.05-4.24$ & 1.56 & $0.68-3.59$ & 0.0529 \\
\hline Vegetable fat (g) & 30.4 & 11.5 & 0.85 & $0.46-1.55$ & 0.62 & $0.31-1.21$ & 0.25 & $0.11-0.57$ & 0.0019 \\
\hline Cholesterol (mg) & 291.8 & 101.8 & 1.10 & $0.57-2.13$ & 1.26 & $0.64-2.48$ & 1.91 & $0.88-4.16$ & 0.0977 \\
\hline \multicolumn{10}{|l|}{ Fatty acids } \\
\hline Saturated fatty acids (g) & 21.8 & 7.6 & 0.59 & $0.31-1.16$ & 1.10 & $0.51-2.38$ & 0.86 & $0.36-2.07$ & 0.9949 \\
\hline Monounsaturated fatty acids (g) & 30.7 & 9.8 & 0.72 & $0.37-1.39$ & 0.89 & $0.45-1.76$ & 0.50 & $0.19-1.28$ & 0.3074 \\
\hline Oleic acid (g) & 28.9 & 9.3 & 0.55 & $0.29-1.06$ & 0.76 & $0.39-1.50$ & 0.45 & $0.18-1.14$ & 0.2196 \\
\hline Polyunsaturated fatty acids (g) & 9.4 & 3.5 & 0.90 & $0.46-1.77$ & 0.76 & $0.37-1.56$ & 0.45 & 0.17-1.19 & 0.1298 \\
\hline Linoleic acid (g) & 7.8 & 3.0 & 1.09 & $0.55-2.15$ & 0.95 & $0.47-1.94$ & 0.54 & $0.20-1.42$ & 0.2812 \\
\hline
\end{tabular}




\begin{tabular}{|c|c|c|c|c|c|c|c|c|c|}
\hline Linolenic acid (g) & 1.1 & 0.4 & 0.61 & $0.32-1.14$ & 0.68 & $0.34-1.37$ & 0.63 & $0.25-1.57$ & 0.3355 \\
\hline Other polyunsaturated fatty acids (g) & 0.5 & 0.2 & 1.55 & $0.82-2.95$ & 1.97 & $1.03-3.80$ & 1.75 & $0.90-3.43$ & 0.0870 \\
\hline \multicolumn{10}{|l|}{ icronutrients } \\
\hline tamin B1 (mg) & 0.9 & 0.3 & 1.45 & $0.77-2.72$ & 1.79 & $0.86-3.72$ & 1.54 & $0.58-4.09$ & 0.2622 \\
\hline $\operatorname{tamin}$ B2 (mg) & 1.4 & 0.4 & 0.96 & $0.48-1.90$ & 0.93 & $0.47-1.85$ & 0.71 & $0.31-1.65$ & 0.4731 \\
\hline tal folate $(\mu \mathrm{g})$ & 304.5 & 103.5 & 0.95 & $0.52-1.72$ & 0.65 & $0.33-1.30$ & 0.41 & $0.18-0.91$ & 0.0334 \\
\hline $\operatorname{tamin}$ C (mg) & 167.2 & 92.1 & 0.93 & $0.50-1.73$ & 0.83 & $0.43-1.61$ & 0.90 & $0.43-1.87$ & 0.6944 \\
\hline $\operatorname{tamin} \mathrm{D}(\mu \mathrm{g})$ & 2.8 & 1.3 & 0.81 & $0.44-1.50$ & 1.48 & $0.76-2.90$ & 0.84 & $0.43-1.66$ & 0.9724 \\
\hline $\operatorname{tamin} \mathrm{E}(\mathrm{mg})$ & 10.7 & 3.7 & 0.87 & $0.49-1.56$ & 0.70 & $0.34-1.31$ & 0.40 & $0.18-0.92$ & 0.0374 \\
\hline tassium (mg) & 3463.3 & 1090.9 & 1.22 & $0.65-2.31$ & 1.28 & $0.62-2.66$ & 1.03 & $0.40-2.67$ & 0.8402 \\
\hline losphorus (mg) & 1280.3 & 359.1 & 1.14 & $0.61-2.14$ & 1.44 & $0.67-3.12$ & 0.67 & $0.23-1.92$ & 0.8423 \\
\hline $\mathrm{nc}(\mathrm{mg})$ & 10.3 & 3.0 & 2.21 & $1.15-4.25$ & 2.63 & $1.21-5.72$ & 2.78 & $1.01-7.83$ & 0.0274 \\
\hline utamic acid (mg) & 16153.5 & 4670.1 & 2.63 & $1.30-5.33$ & 2.09 & $0.92-4.73$ & 3.63 & $1.08-12.20$ & 0.0684 \\
\hline ta-carotene equivalents ( $\mu \mathrm{g}$ ) & 4254.85 & 2376.19 & 1.01 & $0.57-1.80$ & 0.72 & $0.38-1.36$ & 0.63 & $0.33-1.22$ & 0.1126 \\
\hline
\end{tabular}

All models were controlled for region, age and sex (matching variables), and adjusted for BMI $\left(<18.5 ; 18.5-24.9 ; 25-29.9 ; \geq 30 \mathrm{~kg} / \mathrm{m}^{2}\right)$, tobacco smoking (ever; never), alcohol drinking (ever; never), coffee consumption (ever; never) and total energy intake (continuous).

SD: standard deviation; OR: odds ratio; Cl: confidence interval. 


\section{References}

Barranco Quintana JL, Allam MF, Serrano Del Castillo A, et al. Alzheimer's disease and coffee: a quantitative review. Neurol Res. 2007;29(1):91-95.

Ross GW, Abbott RD, Petrovitch H, et al. Association of coffee and caffeine intake with the risk of Parkinson disease. JAMA . 2000;283(20):2674-2679. 